\title{
Response effects of response-dependent and clock-dependent fixed-interval schedules of reinforcement*
}

\author{
ARTHUR G. SNAPPER and ELIOT H. SHIMOFF $\dagger$ \\ FDR Veterans Administration Hospital, Montrose, N.Y. 10548 \\ and \\ WILLIAM N. SCHOENFELD \\ Queens College of the C.U.N.Y. \\ and Cornell University Medical College, New York, N.Y. 10021
}

Each of two groups of 16 rats were trained under fixed-interval schedules of positive reinforcement. One of these schedules was programmed "by the response," in that each 3-min interval was timed from the end of the preceding reinforcement. The other schedule was programmed "by the clock," with periods of reinforcement availability occurring every 3 min after the start of the session. Comparisons of response rate and of measures of temporal discrimination revealed no significant differences in performance under the two procedures. Rank order correlations were found to be significant between two measures of temporal discrimination, but there was no significant correlation between response rate and temporal discrimination across the 32 rats.

Fixed-interval (FI) schedules of reinforcement may be programmed either "by the clock" or "by the response" (Skinner, 1938). In both types of FI, the first response to be emitted on completion of a specified interval is reinforced, while responses emitted during the interval are not. The difference between the two procedures is the event marking the beginning of the interval. In FI by the response [FI(R)], each interval of $n$ sec begins with the reinforced response (or with the end of the reinforcement); in FI by the clock [FI(T)], each interval is timed from the end of the preceding interval regardless of when the reinforced response occurs. It has been reported (Skinner, 1938; Ferster \& Skinner, 1957) that there is usually no difference in behavior maintained by the two schedules because the high rate of responding, which routinely is seen at the ends of intervals, insures that reinforcements are secured as soon as available. The present data provide comparisons of the behavioral effects of the two procedures under equivalent parameters. METHOD

The Ss were 32 male Charles River $C D$ rats, maintained by water deprivation at approximately $80 \%$ of

* Supported in part by Grant MH 13049 from the National Institute of Mental Health, U.S. Public Health Service, and in part by the Veterans Administration. We wish to thank Mr. Robert Vreeland for aid in data analysis. Reprints may be obtained from the Psychology Research Laboratory, FDR Veterans Administration Hospital, Montrose, N.Y. 10548.

+ Now at the University of Maryland, Baltimore County. their free-feeding weights. Food was always available in the home cages. The rats were 90.100 days old at the start of the experiment.

Four standard commercial test chambers (Scientific Prototype Model A-100), housed in ventilated sound-attenuating shells, were used. Each reinforcement consisted of 4 -sec access to a dipper containing $0.1 \mathrm{cc}$ of Alba skim milk. Some acoustic masking was provided by a white noise generator. Experimental contingencies and data recording were controlled by a PDP-8 digital computer, using a system described by Snapper \& Kadden (in press).

Following initial training with continuous reinforcement (CRF), FI $30 \mathrm{sec}$ and FI $1 \mathrm{~min}$, successively, the Ss were exposed to the terminal FI $3 \mathrm{~min}$ schedule for 3 months. Six teeen Ss were exposed to FI(T) and 16 to FI(R). Sessions were held daily and terminated following either $63 \mathrm{~min}$ or 20 reinforcements, whichever came first.

The two methods of programming FI are shown in Fig. 1 as state diagrams (Snapper, Knapp, \& Kushner, 1970). Portions of the experimental session are shown as circles or "states," each having its associated stimuli, with arrows indicating transitions from one state to another. The upper panel depicts FI(R): In State 1 (S1), responses have no programmed effects; after $3 \mathrm{~min}, \mathrm{~S} 2$ is initiated by the clock of $S 1$; the first response in $S 2$ initiates $S 3$, the reinforcement state; 4 sec later, reinforcement ends and the cycle is restarted. The lower panel, FI(T), is identical, with the exception that the transition from $\mathrm{S} 1$ to $\mathbf{S 2}$ is caused by a
" $Z$ " pulse generated every 3 min by an external timer. Since the $\mathrm{Z}$ timer runs independently of behavior, a long latency of response in $S 2$ could result in immediate reinforcement availability following the end of the previous reinforcement. Thus, FI(R) specifies the minimal interreinforcement time, while the clock procedure specifies the maximum time between availabilities of reinforcement.

\section{RESULTS}

Data were collected for the final 10 sessions from each rat, and four measures of responding were examined as follows: (1) Response rate was calculated for each session. (2) A modified form of quarter-life (QL) (Herrnstein \& Morse, 1957; Gollub, 1964) expressed the mean time taken by $25 \%$ of the responses in the interval as a percentage of the specified interval (i.e., in this case, $3 \mathrm{~min}$ ). (3) The index of curvature (CI) (Fry, Kelleher, \& Cook, 1960) reflected the extent and direction of the deviation of responding within any interval from a constant response rate. In the calculation of $Q \mathrm{~L}$ and $\mathrm{CI}$, response rates were separately tabulated for $\mathbf{1 2}$ successive 15-sec subintervals of the 3-min FI. Both QL and CI were originally defined as measures of a single FI interval, but the values presented in the current study are means of 20 daily intervals, since Gollub has shown a high correlation between session measures and those from individual intervals. (4) Finally, latency, or time from the beginning of availability of reinforcement (when the next response would be reinforced) to the time of occurrence of the reinforced response, i.e., the

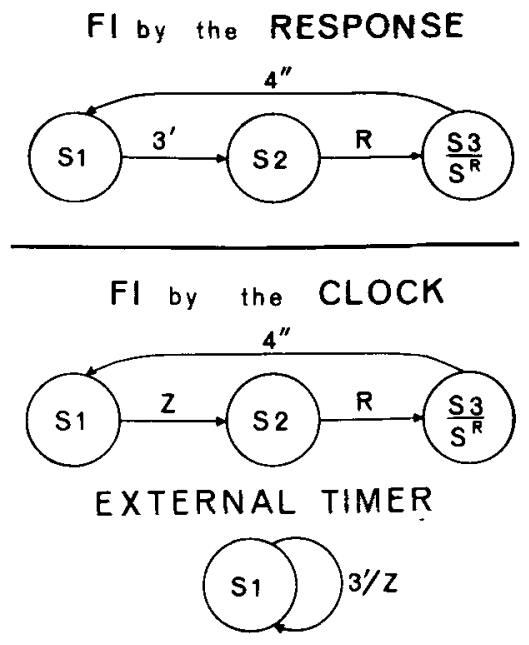

Fig. 1. State diagrams of the two different FI procedures. Upper panel represents FI(R), the lower panel, FI(T). 
Table 1

Means and Coefficients of Variation of Each Response Measure for the Last 10 Sessions Under FI(R)

\begin{tabular}{|c|c|c|c|c|c|c|c|c|}
\hline \multirow[b]{2}{*}{ Rat } & \multicolumn{2}{|c|}{ Rate } & \multicolumn{2}{|c|}{ QL } & \multicolumn{2}{|c|}{ CI } & \multicolumn{2}{|c|}{ Latency } \\
\hline & $\mathbf{M}$ & V & $\mathbf{M}$ & V & $\mathbf{M}$ & $\mathbf{V}$ & $\mathbf{M}$ & V \\
\hline 1 & 15.61 & .07 & 68.96 & .03 & .56 & .04 & 0.9 & .28 \\
\hline 2 & 23.26 & .10 & 70.52 & .03 & .58 & .05 & 1.0 & .24 \\
\hline 3 & 7.67 & .18 & 68.99 & .07 & .55 & .09 & 1.7 & .35 \\
\hline 4 & 25.60 & .08 & 74.29 & .01 & .64 & .03 & 0.8 & .48 \\
\hline 5 & 10.36 & .30 & 66.78 & .05 & .54 & .09 & 2.0 & .61 \\
\hline 6 & 32.55 & .12 & 75.21 & .02 & .65 & .03 & 0.5 & .23 \\
\hline 7 & 8.96 & .25 & 75.96 & .08 & .65 & .12 & 1.8 & .47 \\
\hline 8 & 14.90 & .11 & 61.57 & .04 & .47 & .06 & 1.1 & .17 \\
\hline 9 & 6.40 & .15 & 62.84 & .08 & .48 & .13 & 3.6 & .60 \\
\hline 10 & 20.36 & .10 & 66.78 & .03 & .54 & .04 & 0.8 & .14 \\
\hline 11 & 10.34 & .17 & 72.85 & .03 & .61 & .05 & 1.6 & .29 \\
\hline 12 & 9.24 & .09 & 70.93 & .04 & .57 & .05 & 1.5 & .27 \\
\hline 13 & 5.10 & .27 & 69.87 & .03 & .58 & .03 & 3.0 & .33 \\
\hline 14 & 3.64 & .32 & 73.55 & .05 & .61 & .08 & 5.0 & .28 \\
\hline 15 & 4.89 & .18 & 66.00 & .02 & .53 & .15 & 3.7 & .28 \\
\hline 16 & 19.07 & .16 & 71.44 & .02 & .60 & .03 & 0.9 & .56 \\
\hline Average & 13.62 & .17 & 69.78 & .04 & .57 & .06 & 1.9 & .35 \\
\hline
\end{tabular}

total amount of time spent in $\mathbf{S 2}$, was response rate and both measures of noted. For each $S$, the mean and coefficient of variation for each of these measures are presented in Tables 1 and 2.

The Welch $\mathrm{T}$ test of mean rate, $\mathrm{QL}$, CI, latency, and coefficient of variation revealed no difference between FI(R) and FI(T) ( $p>.80$, in all cases). The coefficients of variation of $C I$ and $Q L$ were smaller than reported by Gollub, but, for 31 of the $32 \mathrm{Ss}, \mathrm{QL}$ was less variable than $\mathrm{CI}$, confirming his comparison of these two measures of temporal discrimination.

Gollub obtained significant correlations between $\mathrm{QL}$ and $\mathrm{CI}$ both for interval-to-interval and session-to-session measures of temporal discrimination. In the present study, QL and CI were significantly correlated (at the .05 level, by rank-order correlations) for

each of the 32 rats across its 10 sessions. Nine Ss had significant, but small negative, correlations between temporal discrimination. Seven Ss had significant negative correlations between rate and latency.

Table 3 presents the rank order correlations across the 32 Ss between paired measures, each measure averaged for each rat across its 10 sessions. QL and $\mathrm{CI}$ are positively correlated, while rate is negatively correlated with latency at the $p<.05$ level.

\section{DISCUSSION}

Our data confirm the suggestions by Skinner (1938) and Ferster \& Skinner (1957) that response patterns generated under $F I(R)$ and $F I(T)$ are very similar, at least for the interval length of $3 \mathrm{~min}$. Given our experimental arrangements, under both schedules temporal

Table 2

Means and Coefficients of Variation of Each Response Measure for the Last 10 Sessions Under FI(T)

\begin{tabular}{|c|c|c|c|c|c|c|c|c|}
\hline \multirow[b]{2}{*}{ Rat } & \multicolumn{2}{|c|}{ Rate } & \multicolumn{2}{|c|}{$\mathbf{Q L}$} & \multicolumn{2}{|c|}{$\mathrm{CI}$} & \multicolumn{2}{|c|}{ Latency } \\
\hline & $\mathbf{M}$ & $\mathbf{V}$ & $\mathbf{M}$ & $\mathbf{V}$ & $\mathbf{M}$ & $\mathbf{V}$ & $\mathbf{M}$ & $\mathbf{V}$ \\
\hline 17 & 6.67 & .14 & 64.58 & .04 & .52 & .06 & 1.9 & .22 \\
\hline 18 & 33.16 & .15 & 65.67 & .05 & .53 & .06 & 0.7 & .74 \\
\hline 19 & 4.86 & .16 & 71.48 & .11 & .63 & .05 & 2.1 & .36 \\
\hline 20 & 3.66 & .14 & 82.87 & .02 & .75 & .03 & 3.6 & .48 \\
\hline 21 & 40.78 & .17 & 73.03 & .05 & .63 & .08 & 0.5 & .78 \\
\hline 22 & 5.94 & .22 & 82.31 & .03 & .71 & .07 & 2.7 & .29 \\
\hline 23 & 8.27 & .18 & 72.43 & .04 & .62 & .06 & 2.3 & .67 \\
\hline 24 & 8.08 & .20 & 81.43 & .06 & .71 & .10 & 2.9 & .78 \\
\hline 25 & 19.54 & .17 & 63.24 & .04 & .48 & .06 & 1.5 & .64 \\
\hline 26 & 1.90 & .15 & 74.19 & .06 & .61 & .11 & 4.0 & .15 \\
\hline 27 & 20.58 & .15 & 67.87 & .03 & .53 & .06 & 1.5 & .45 \\
\hline 28 & 18.34 & .09 & 75.02 & .02 & .65 & .03 & 1.4 & .40 \\
\hline 29 & 38.19 & .21 & 66.42 & .04 & .54 & .06 & 0.6 & .32 \\
\hline 30 & 8.92 & .16 & 72.72 & .04 & .59 & .05 & 1.5 & .54 \\
\hline 31 & 7.37 & .09 & 55.75 & .05 & .41 & .05 & 2.7 & .34 \\
\hline 32 & 5.33 & .11 & 72.67 & .02 & .62 & .02 & 1.6 & .25 \\
\hline Average & 14.47 & .16 & 71.36 & .04 & .60 & .06 & 2.0 & .46 \\
\hline
\end{tabular}

discriminations may alter the final performance under the two procedures if an imposed variable interacts with the basic differences in the microstructure of the two schedules. For example, a stimulus intruded in the middle of alternate FI intervals may lower response rate during the interval in which it occurs. Under F I ( R ), t h e m i n i m u m interreinforcement time of the next interval would remain reinforcements could follow each other in quick succession if the stimulus-induced delay in responding were to extend far enough into the next interval. If this pattern of a long poststimulus delay followed by two closely spaced reinforcements were maintained for some time, the two FI procedures might well fixate quite different patterns of responding.

Gollub (1964) concluded, from the lack of correlation between response rate and temporal discrimination, that both types of information are necessary to characterize FI performance fully. Besides confirming

Table 3

Rank Order Correlations Between Measures Across $32 \mathrm{~S}$.

\begin{tabular}{lcc}
\hline & $\begin{array}{c}\text { FI } \\
\text { Response }\end{array}$ & $\begin{array}{c}\text { FI } \\
\text { Clock }\end{array}$ \\
\hline Rate vs QL & .290 & -.294 \\
Rate vs CI & .363 & -.275 \\
Rate vs Latency & $-.778^{*}$ & $-.818^{*}$ \\
QL vs CI & $.989^{*}$ & $.984^{*}$ \\
QL vs Latency & -.169 & .396 \\
CI vs Latency & .211 & .366 \\
\hline
\end{tabular}

*p at least less than .05 level.

this point, the present data permit conclusions concerning variability across Ss. Some workers have reported that FI responding ultimately becomes bivalued, i.e., a zero rate occurs early in the interval (generally, immediately after the reinforcement) and is abruptly replaced by a high steady rate that continues until the next reinforcement (Cumming \& Schoenfeld, 1958; Schnieder, 1969). Rate variability could then result from different terminal rates, from different points of transition within the interval, or from a combination of both. The similarity of the indices of temporal discrimination across 32 rats, despite considerable overall rate variability, argues that neither differences in terminal rates nor in the transition points alone are responsible for the overall rate differences, since either factor operating without compensation in the other would result in large differences in both $\mathrm{QL}$ and CI. Our finding of consistency in these measures, despite variability in 
overall response rate, suggests rather that, if the sum of responses in any interval is broken down into the 12 15-sec subintervals and expressed for each subinterval as percentages of the total, then the distribution of responses across the subintervals is similar for all Ss.

REFERENCES

CUMMING, w. W \& SCHOENFELD, $\mathbf{w}, \mathbf{N}$ Behavior under extended exposure to a high-value fixed interval reinforcement schedule. Journal of the Experimental Analysis of Behavior, 1958, 1, 245-263. FERSTER, C. B. \& SKINNER, B. F Schedules of reinforcement. New York: Appleton-Century-Crofts, 1957.

FRY, W., KELLEHER, R. T., \& COOK. L. A mathematical index of performance on fixed-interval schedules of reinforcement. Journal of the Experimental Analysis of Behavior, 1960, 3, 193-199.
GOLLUB, $L$, The relations among measures of performance on fixed-interval schedules. Journal of the Experimental Analysis of Behavior, 1964. 7, 337-343.

HERRNSTEIN, R. J., \& MORSE, W. H Effects of pentobarbital on intermittently reinforced behavior. Science, 1957, 125 . 929-931.

SCHNEIDER, B. A. A two-state analysis of fixed-interval responding in the pigeon. Journal of the Experimental Analysis of Behavior, 1969, 12, 677-687.

SKINNER, B. F. The behavior of organisms. New York: Appleton-Century-Crofts, 1938

SNAPPER, A. G., \& KADDEN, R. M. Time-sharing in a small computer through the use of a behavioral notation system. In $B$. Weiss (Ed.) Digital computers in the behavior laboratory. New York: Appleton-Century-Crofts, in press.

SNAPPER, A. G., KNAPP, J. Z., \& KUSHNER, H. K. Mathematical description of schedules of reinforcement. In W. N. Schoenfeld (Ed.), The theory of reinforcement schedules. New York: Appleton-Century-Crofts. 1970. Pp. 247-275.

\section{The effects of prefear conditioning shock intensity on initial shuttle response rate}

\author{
GEORGE A. CICALA and RONALD R. ULM \\ University of Delaware, Newark, Del. 19711
}

The effects of prefear conditioning shock intensity on unreinforced shuttle response rate indicated that unreinforced shuttle response is inversely related to prefear shock intensity. The CS enhanced shuttling equally for all prefear shock groups. The data suggest that prefear conditioning decreases initial shuttle response rate, while the CS partially reverses this effect. An interpretation of demonstrated facilitation by prefear conditioning is offered.

Shuttle avoidance learning has been shown to be inversely related to shock intensity (Moyer \& Korn, 1964; Cicala \& Kremer, 1969) and directly related to intertrial interval (ITI) duration (Murphy \& Miller, 1956; Brush, 1962). A recent experiment (Cicala, Ulm, \& Drews, 1971) demonstrated that these effects emerge in shuttle-avoidance responding in the absence of escape or avoidance contingencies. This finding suggests that shock intensity and ITI duration affect shuttle-avoidance learning by modifying the operant level of the shuttle response, providing differential probabilities of response reinforcement.

Other manipulations may also modify the unreinforced shuttle rate and thereby exert their influence on a voidance learning. For example, prefear conditioning has usually been shown to facilitate the acquisition of shuttle responding (Slotnick, 1968; Baum, 1969), although this facilitation has not always been obtained (Mullin \& Mogenson, 1963; Weiss, Krieckhaus, \& Conte, 1968). Facilitation is usually interpreted in terms of the motivating effects of CS introduction and the reinforcing effects of CS termination in prefear conditioned Ss. Alternatively, it is conceivable that prefear conditioning may increase the initial response rate to the $\mathrm{CS}$ and thereby facilitate avoidance learning. The present experiment was designed to test this hypothesis.

\section{SUBJECTS}

Sixty-three male Wistar rats, 90-110 days old, were used.

\section{APPARATUS}

A test cage constructed entirely of stainless steel grids spaced $1 / 2$ in. apart in a Plexiglas frame, 9 in. long, $7 \frac{1}{2}$ in. wide, and $6^{1 / 2} \mathrm{in}$. high, was used. All of the grids were wired for shock. A speaker directed at the test cage was mounted in the top of a sound-attenuating test cage enclosure. A variable-output, $150-\mathrm{K}$-ohm, fixed-impedance shock source (Campbell \& Masterson, 1969) provided the shock stimuli. Interruptions of a photocell beam bounced across the width of the test cage recorded crossings.

\section{PROCEDURE}

The Ss were divided into eight experimental groups and assigned to a 4 by 2 factorial matrix, varying shock intensity $(45,90,180$, and $360 \mathrm{~V})$ and shock duration $(.5$ and $3 \mathrm{sec})$. During prefear conditioning, each $S$ was placed in the test cage and, after $2 \mathrm{~min}$, was given 10 presentations of a 10-sec 80-dB white-noise CS which terminated with the onset of shock. A control group of seven rats was given $10 \mathrm{CS}$ presentations without shock. The intertrial interval was $20 \mathrm{sec}$ for all groups.

Twenty-four hours after prefear conditioning, Ss were tested by being placed in the test cage and presented with the $10-\sec \mathrm{CS}$ for 10 trials, again separated by a 20-sec ITI. No shock was presented. Crossings, measured by photocell interruptions, served as the index of unreinforced avoidance responding during testing. This measure was taken during the 10 -sec CS period (CS-on) and during the 20-sec ITI betweeen CS presentations. Since the ITI was twice as long as CS-on, activity during ITI was halved (CS-off).

\section{RESULTS AND DISCUSSION}

Mean crossing scores were analyzed by an analysis of variance for factorial experiments using a single control group (Winer, 1962, p. 264). The effects of prefear shock intensity, prefear shock duration, and CS-on vs CS-off were assessed. This analysis showed that prefear shock intensity and presence or absence of CS significantly affected crossing scores $(\mathrm{F}=17.38, \quad \mathrm{df}=4 / 62, \quad \mathrm{p}<.01 ;$ $\mathrm{F}=14.60, \quad \mathrm{df}=1 / 62, \quad \mathrm{p}<.01$; respectively), while prefear shock duration was not significant. None of the interactions was significant.

The main results are presented in Fig. 1, which shows mean crossings during CS-on and during CS-off for 10 CS presentations as a function of prefear shock voltage. Each point is a mean score for all Ss regardless of the prefear shock duration employed. Crossings during CS-on and during CS-off are linearly and inversely related to shock intensity, while crossing rate during CS-on is higher at all shock intensities than during CS-off.

If shuttling in the presence of the CS can be viewed as an index of initial avoidance response rate, the data clearly imply that prefear conditioning under high shock intensity would result in a lower initial avoidance response rate than under low shock intensity or in the absence of shock. However, mean crossing rate during CS-on is not truly analogous to the usual measure of avoidance responding, which is the occurrence of a single crossing on a particular trial. To provide a measure of initial 